\title{
The Bacillus subtilis lipoprotein LplA causes cell lysis when expressed in Escherichia coli
}

\author{
Ana Gómez, Daniel Ramón and Pascual Sanz
}

Instituto de Agroquímica y Tecnología de los Alimentos (CSIC), Jaime Roig 11, 46010Valencia, Spain

\author{
Author for correspondence: Pascual Sanz. Tel: +346 3690800. Fax: +34 63930001 \\ e-mail: HONGOS@IATA.CSIC.ES
}

\begin{abstract}
A gene called IpIA (lipoprotein-like) has been isolated from a genomic library of Bacillus subtilis expressed in Escherichia coli. Clones carrying the IpIA gene were selected by the ability of the colonies to give visible haloes of starch hydrolysis. The cloned fragment contains an open reading frame (ORF) of 1509 bp encoding a protein of $56 \mathrm{kDa}$. The protein contains a typical $\mathbf{N}$-terminal signal sequence, a putative transmembrane anchor domain and a leucine zipper at the C-terminus. The expression of this protein in E. coli causes cell lysis, only the $\mathrm{N}$-terminal domain of the LpIA protein being responsible for this phenotype. The mechanism of cell lysis is similar to that previously suggested for the expression in E. coli of the lipoproteins encoded by the Streptococcus pneumoniae genes malX and amiA. The protein is modified with palmitic acid when secreted in $E$. coli, confirming that it is a typical lipoprotein.
\end{abstract}

Keywords: IplA, lipoprotein, cell lysis, Bacillus subtilis

\section{INTRODUCTION}

Many species in the genus Bacillus synthesize one or more extracellular amylases (Priest, 1977). Bacillus subtilis synthesizes an $\alpha$-amylase (AmyE) that is one of the major extracellular enzymes (Yang et al., 1983). This work was originally oriented to the isolation of new amylolytic enzymes from $B$. subtilis; we therefore constructed a genomic library from this organism and expressed it in $E$. coli. To our surprise, one of the clones initially selected as amylolytic carried a B. subtilis gene whose expression in Escherichia coli caused cell lysis. We suggest that this gene codes for a putative lipoprotein-like protein, since it behaves in a similar way to the Streptococcus pneumoniae lipoprotein genes malX and amiA (Martin et al., 1989) when expressed in E. coli. In this paper we describe the isolation of the $B$. subtilis lpl $A$ gene and the phenotypic characterization of the protein that it encodes.

\section{METHODS}

Bacterial strains, plasmids and culture conditions. The bacterial strains and plasmids used in this work are listed in Table 1. In general, B. subtilis and E. coli strains were grown in LB broth or plates. Ampicillin was used at a concentration of $50 \mu \mathrm{g} \mathrm{ml}^{-1}$ and chloramphenicol was used at $5 \mu \mathrm{g} \mathrm{ml}^{-1}$ for both E. coli and B. subtilis; erythromycin was used at a concentration of $10 \mu \mathrm{g} \mathrm{m} l^{-1}$ for B. subtilis and $100 \mu \mathrm{g} \mathrm{ml}^{-1}$ for E. coli.

The GenBank accession number for the sequence reported in this paper is L03376.
General cloning procedures. We followed the techniques described in Sambrook et al. (1989). Restriction enzymes, T4 DNA ligase, Klenow polymerase and calf alkaline phosphatase were from Promega.

Construction of the genomic library. Chromosomal DNA from $B$. subtilis and plasmid DNA from E. coli were purified following standard procedures (Marmur, 1961; Sambrook et al., 1989). The DNA from B. subtilis was partially digested with the endonuclease Sau3A and electrophoresed in a preparative agarose gel. Fragments ranging from 3 to $9 \mathrm{~kb}$ were recovered by electroelution. The purified DNA was ligated to pBR322, previously cut with Bam HI and dephosphorylated with calf alkaline phosphatase. The ligation mixture was used to transform E. coli $\mathrm{DH} 5 \alpha$. Around 25000 transformants containing inserts of the $B$. subtilis chromosome were obtained. From those, around 2400 transformants giving tiny colonies were initially selected and plated on selective media (LB supplemented with $50 \mu \mathrm{g}$ ampicillin $\mathrm{ml}^{-1}$ and $1 \%, \mathrm{w} / \mathrm{v}$, insoluble starch).

Transformation methods. E. coli cells were made competent and transformed following the method described in Hanahan (1983), with some modifications. B. subtilis cells were made competent as described in Bron \& Luxen (1985), and transformed with 1-5 $\mu \mathrm{g}$ DNA for $45 \mathrm{~min}$ at $37^{\circ} \mathrm{C}$; then the cells were diluted twofold with $\mathrm{LB}$ broth and incubated at $30^{\circ} \mathrm{C}$ (erythromycin selection) or $37^{\circ} \mathrm{C}$ (chloramphenicol selection) for $90 \mathrm{~min}$ to allow expression of antibiotic resistance markers. Transformants were selected on LB plates supplemented with antibiotics at appropriate concentrations.

Detection of starch hydrolysis on plates. Recombinant clones from the $B$. subtilis library were tooth-picked on LB medium supplemented with $50 \mu \mathrm{g}$ ampicillin $\mathrm{ml}^{-1}$ and $1 \%(\mathrm{w} / \mathrm{v})$ insoluble starch (Sigma). Incubation of plates was carried out at 
Table 1. Bacterial strains and plasmids

\begin{tabular}{|c|c|c|}
\hline Material & Relevant features & Source or reference \\
\hline \multicolumn{3}{|l|}{ Strains } \\
\hline E. coli $\mathrm{DH} 5 \alpha$ & supE44 $\Delta l a c U 169$ bsd $\mathrm{R} 17 \mathrm{rec} A 1$ end $A 1$ gyr $A 96$ thi-1 rel $A 1$ & Hanahan (1983) \\
\hline \multicolumn{3}{|l|}{ Bacillus subtilis } \\
\hline Type strain & Wild-type & CECT 0039 \\
\hline MB11 & amy lys-3 metB10 bisH2 & Dr Espinosa, CIB, Madrid \\
\hline DB104 & amy bisH npr18 nprR2 apa $A 3$ & Pérez-Martinez et al. (1992) \\
\hline \multicolumn{3}{|l|}{ Plasmids } \\
\hline pBR322 & E. coli vector & Bolivar et al. (1977) \\
\hline pC194 & B. subtilis vector & Horinouchi \& Weisblum (1982) \\
\hline pGA14 & B. subtilis vector & Pérez-Martinez et al. (1992) \\
\hline pUC13, pUC18 & E. coli vector & Messing (1983) \\
\hline pCUC & pC194 + pUC18 & This work \\
\hline PAMY & pCUC $+B$. licbeniformis $\alpha$-amylase gene & This work \\
\hline PLPLA & pCUC $+4.5 \mathrm{~kb}$ EcoRI-EcoRI insert ${ }^{*}$ & This work \\
\hline pEm1 & pUC13+erm $C$ gene & This work \\
\hline $\mathrm{pEm} 2$ & $\mathrm{pEm} 1+536$ bp central fragment of $l p l A$ & This work \\
\hline $\mathrm{pA}-1$ & pBR $322+6.7 \mathrm{~kb}$ Sau $3 \mathrm{~A}-\operatorname{Sau} 3 \mathrm{~A}$ insert & This work \\
\hline pAE-1 & pUC13 + $4.5 \mathrm{~kb}$ EcoRI-EcoRI insert & This work \\
\hline pAEP-1 & PUC13 $+2 \cdot 1 \mathrm{~kb}$ EcoRI-PvuII insert & This work \\
\hline PAEP-2 & pUC18 $+2 \cdot 1 \mathrm{~kb}$ EcoRI-PvuII insert & This work \\
\hline pAES-1 & pUC13 + 1.6 EcoRI-SacI insert & This work \\
\hline pAES-1 $1 \Delta 1$ & See details in the text & This work \\
\hline pAES- $1 \Delta 2$ & See details in the text & This work \\
\hline
\end{tabular}

* The insert refers to DNA fragments containing the complete or partial sequences of the $l p l A$ gene.

$37^{\circ} \mathrm{C}$ : after $24 \mathrm{~h}$, clones that showed a halo of starch hydrolysis were selected.

Southern blot hybridization. In each case, chromosomal or plasmid DNA was digested with the desired restriction enzymes and subjected to electrophoresis on $0.7 \%(\mathrm{w} / \mathrm{v})$ agarose gels. The separated fragments were visualized by staining with ethidium bromide and transferred to a Hybond- $\mathrm{N}$ membrane (Amersham), following the standard procedure. DNA probes were labelled with $\left[\alpha_{-}^{32} \mathrm{P}\right] \mathrm{dCTP}$ using the random primed labelling kit from Boehringer Mannheim. Hybridizations were carried out by standard procedures (Sambrook et al., 1989).

DNA sequencing. DNA sequencing was done by the dideoxynucleotide chain termination procedure (Sanger et al., 1977) with the Sequenase enzyme (USB). Unidirectional, sequential deletions in plasmid pAES-1 were obtained by the exonucleaseIII-S1 nuclease digestion protocol (Henikoff, 1984), using a kit from Pharmacia. In some cases specific restriction fragments cloned into $\mathrm{pUC}$ vectors were used as templates in the sequencing reactions.

Analysis of sequence data. Analysis of DNA and protein sequence data was carried out with the DNASIS, PROSIS (Pharmacia) and GCG (Devereux et al., 1984) packages. The National Biomedical Research Foundation-Protein Identification Resource (NBRF-PIR), SwissProt, EMBL and GenBank were the databases used for protein and DNA homology searches.

Isocitrate dehydrogenase assay. Isocitrate dehydrogenase was measured as in Smith et al. (1987).

Incorporation of $\left[{ }^{3} \mathrm{H}\right]$ palmitic acid. E. coli cells carrying different plasmids and growing exponentially were incubated with $\left[9,10(\mathrm{n})-{ }^{3} \mathrm{H}\right]$ palmitic acid $\left(20 \mu \mathrm{Ci} \mathrm{m}^{-1}\right)$ (Amersham) at $37^{\circ} \mathrm{C}$ for $1 \mathrm{~h}$. Cells were harvested and washed four times with distilled water to remove unincorporated radioactive precursor. Finally, cells were boiled in SDS-loading buffer and the extracted proteins analysed by SDS-PAGE and fluorography.

Construction of the Bacillus subtilis integrative plasmids pEm1 and pEm2. pEm1 was obtained by ligating an EcoRI-SacI fragment containing the erythromycin resistance gene $\mathrm{erm}^{\mathrm{R}}$ from plasmid pGA14, in pUC13 previously digested with the same set of enzymes. A HindIII-EcoRV fragment from the sequencing deletion clone $\mathrm{t} 7.12$ containing $536 \mathrm{bp}$ of the central sequence of $l p l A$ (Fig. 1) was subcloned into $\mathrm{pEm} 1$ previously digested with HindIII and EcoRV, giving the plasmid pEm2.

\section{RESULTS}

\section{Cloning of B. subtilis DNA fragments conferring starch hydrolytic ability}

Initially, the cloning strategy was designed to isolate $E$. coli transformants that were able to express amylolytic enzymes. In this way, a $B$. subtilis DNA genomic library was constructed in $\mathrm{pBR} 322$. Since the expression of heterologous $\alpha$-amylases in $E$. coli is sometimes toxic (Willemot \& Cornelis, 1983; Yang et al., 1983), of 25000 transformants originally obtained, 2400 were initially selected as giving tiny colonies, and plated on selective media (LB supplemented with $50 \mu \mathrm{g}$ ampicillin $\mathrm{ml}^{-1}$ and $1 \%, \mathrm{w} / \mathrm{v}$, insoluble starch). From these, only 15 transformants showed a clear starch hydrolysis phenotype.

Plasmid DNA isolated from these clones showed an insert size that ranged from 2.7 to $6.7 \mathrm{~kb}$. A $2.1 \mathrm{~kb} E c o$ RI-P $v u \mathrm{II}$ fragment from the insert of one of these clones was 
(a)

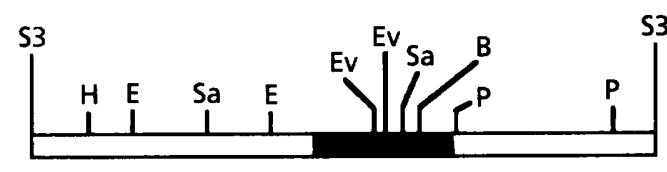

PEM2 $\stackrel{I p \mid A}{\longmapsto}$ $1 \mathrm{~kb}$

(b)

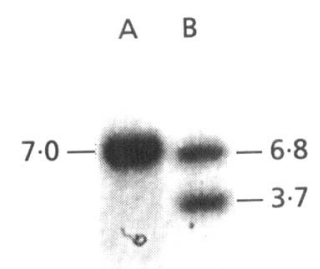

Fig. 1. (a) Restriction map of the $6.7 \mathrm{~kb}$ insert contained in $\mathrm{pA}$ 1. B, Banll; E, EcoRI; Ev, EcoRV; H, HindIII; P, Pvull; Sa, Sacl; S3, Sau3A1. The filled box shows the gene. The 536 bp fragment used in disruption experiments is also shown (pEm2). (b) Southern blot analysis of the $B$. subtilis wild-type and a disrupted strain. Genomic DNA from the wild-type (A) and a disrupted transformant (B) were digested with HindlII. The EcoRI-Pvull fragment of the Ip/A gene was used as a probe. Molecular markers (not shown) were used to determine the size of the bands $(\mathrm{kb})$.

labelled with $\left[\alpha^{-32} \mathrm{P}\right] \mathrm{dCTP}$ and used to hybridize a Southern blot of the plasmid DNA from all the selected clones. All the clones showed a cross-hybridization with the probe. So, the original clone, named pA-1, was chosen for further studies and its restriction map was constructed (see Fig. 1a). The same probe was used to hybridize a Southern blot that contained totally digested genomic DNA from B. subtilis. In Fig. 1(b), it can be seen that the probe hybridized with one HindIII band of $7.0 \mathrm{~kb}$, demonstrating that the insert was truly a piece of $B$. subtilis DNA.

\section{Molecular analysis of the cloned gene}

The subcloning of the insert contained in pA-1 demonstrated that the EcoRI-PvuII fragment of $2 \cdot 1 \mathrm{~kb}$ was capable of conferring the starch hydrolysis phenotype, suggesting that this fragment contained the gene and its own promoter that allowed expression in $E$. coli. This fragment was cloned in pUC13 and pUC18, giving the plasmids pAEP-1 and pAEP-2 respectively.

To determine the nucleotide sequence of the cloned gene, partial digestion with exonuclease III was used to generate overlapping deletion clones. The $2 \cdot 1 \mathrm{~kb}$ EcoRI-PvuII fragment was sequenced from both strands (Fig. 2); it revealed an ORF of $1509 \mathrm{bp}$. We called the gene $l p l A$ (see below for the explanation). The $l p l A$ gene coded for a 502 amino acid $(56 \mathrm{kDa})$ protein with several interesting properties: (i) a putative signal sequence at the $\mathrm{N}$-terminus (amino acids 1-21); (ii) a putative transmembranal anchor domain (amino acid 201-225) according to the hydropathy analysis plot (Hoop \& Wood, 1981) (data not shown); and (iii) a putative leucine zipper (amino acid 384-433) with eight Leu or Ile residues.

In the $5^{\prime}$ upstream untranslated region, typical $B$. subtilis vegetative promoter regions were found $(a-35$ region and a -10 TATA box) and also a ribosome binding domain close to the ATG. However, in the $3^{\prime}$ downstream region we could not find any transcriptional terminator related sequence.

Surprisingly, neither the protein nor the nucleotide sequence showed homologies with any of the amylases whose sequences have been published, or to any protein or nucleotide sequence in the GenBank, EMBL, SwissProt or NBRF databases.

\section{The B. subtilis IpIA gene does not code for any amylase}

To determine whether the cloned gene encoded an amylase, we expressed it in different $\mathrm{Amy}^{-} B$. subtilis strains. A $4.5 \mathrm{~kb}$ EcoRI-EcoRI fragment from $\mathrm{pA}-1$ containing the whole gene and the regulatory sequences was subcloned in pUC13 and the resulting plasmid, named pAE-1, was cut with HindIII and ligated with HindIII-digested pC194, a typical B. subtilis vector. The resulting plasmid was named $\mathrm{pLPLA}$. A negative control was constructed by digesting pC194 with HindIII, bluntending with Klenow polymerase and then ligating with pUC18 previously digested with ScaI. This plasmid was named pCUC. A positive control, named pAMY, was constructed by introducing in pCUC a $2 \mathrm{~kb}$ EcoRI-HindIII fragment from plasmid pGA14, which contained the $\alpha$-amylase gene from $B$. licheniformis. The three plasmids were used to transform two Amy ${ }^{-}$strains of $B$. subtilis (MB11 and DB104). Only when pAMY was used were amylolytic transformants obtained. Using pLPLA, none of the transformants showed any amylolytic phenotype.

Another way to determine if the isolated gene coded for an amylolytic enzyme was to disrupt the wild-type allele of the gene and then test whether the disrupted strain was able to show the original amylolytic phenotype. From a sequencing deletion clone, a 536 bp fragment corresponding to the central domain of the gene (Fig. 1a) was subcloned in $\mathrm{pEm} 1$, an integrative vector containing the $B$. subtilis erythromycin resistance marker. The resulting plasmid ( $\mathrm{pEm} 2$ ) was used to transform the B. subtilis wildtype strain, and the disrupted transformants were selected by their ability to grow on erythromycin. The disruption was checked by Southern blot analysis (Fig. 1b). Transformants showed the two expected HindIII bands of 6.8 and $3.7 \mathrm{~kb}$ as predicted by the integration of the $\mathrm{pEm} 2$ 


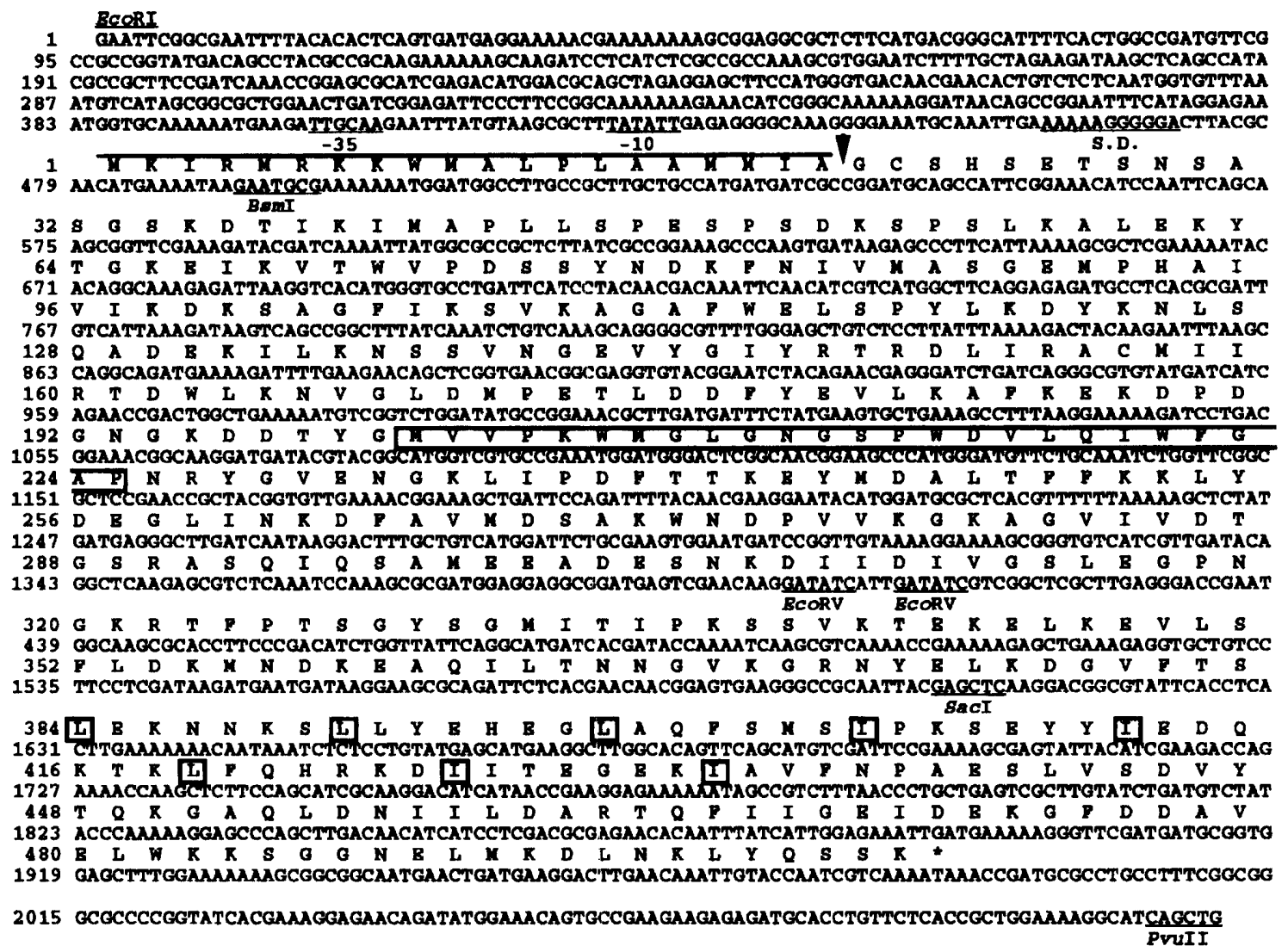

Fig. 2. Nucleotide sequence of the $I p / A$ gene and its deduced amino acid sequence. The typical vegetative promoter regions and the ribosome binding domain are underlined. The putative signal sequence is overlined and the arrow shows the putative cleavage site. The transmembrane anchor domain is boxed and the amino acids involved in the putative leucine zipper are also boxed.

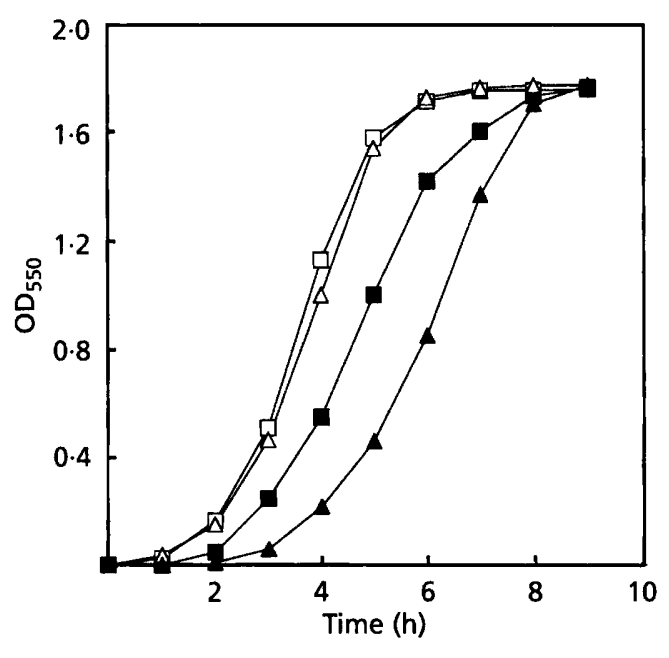

Fig. 3. Growth curves of E. coli $\mathrm{DH} 5 \alpha$ transformed with different plasmids. $\square$, pBR322; $\square, \mathrm{pA}-1 ; \triangle$, pUCI3; $\triangle$, pAE-1.

plasmid into the $B$. subtilis chromosome. The disrupted strain showed the same level of amylolytic activity as the wild-type strain, in both solid and liquid culture. This confirmed that the cloned gene was not involved in starch degradation and did not code for an amylase. Also, the disrupted transformant showed no differences with respect to the wild-type strain in colony morphology, the profile of sugar assimilation (tested using a API $50 \mathrm{CH}$ strip), growth kinetics, and sporulation capability (data not shown). Thus, the cloned gene appeared not to be involved in any vital cell function.

\section{The expression of the IpIA gene in E. coli causes cell lysis}

If the B. subtilis lplA gene was not involved in the amylolytic system of this micro-organism, why did we isolate a plasmid containing it from $E$. coli cells that showed a clear amylolytic phenotype? The most plausible explanation was that the expression of the gene caused cell lysis and that the periplasmic or cytoplasmic $\alpha$-amylases and the cytoplasmic amylomaltase of E. coli (Schwartz, 1987; Raha et al., 1992) were released to the medium, producing the characteristic amylolytic phenotype. To investigate this, we followed the appearance of a cytosolic marker, isocitrate dehydrogenase activity, in the culture medium. E. coli DH5 $\alpha$ was transformed with pAE-1 and pUC13, and the transformants were grown on LB with ampicillin. An increase in the amount of isocitrate dehydrogenase was detected in the culture media of cells 
containing the $l p l A$ gene $\left(0.4 \mathrm{mU} \mathrm{l}^{-1}\right.$ in pUC13 transformed cells versus $2 \cdot 0 \mathrm{mU} \mathrm{l}^{-1}$ in pAE-1 transformed cells). Although this amount was only around $13 \%$ of the total enzyme found when the cells carrying pAE-1 were broken with glass beads, it seemed that this percentage of cell lysis was enough to release cellular contents and cause visible haloes of starch hydrolysis.

The growth kinetics were also studied in E. coli $\mathrm{DH} 5 \alpha$ transformed with regular (pBR322 and pA-1) or high copy (pUC13 and pAE-1) number plasmids. As shown in Fig. 3 , the growth curves of the strains carrying the $l p l A$ gene were delayed with respect to those of the strains carrying the vector alone. The delay was higher in the strain carrying the pAE-1 high copy number plasmid. After $6 \mathrm{~h}$ growth in selective media, we studied the presence of the 'amylolytic phenotype' in the cells and found that in the case of $\mathrm{pA}-1$, the proportion of cells that showed an 'amylolytic phenotype' was $100 \%$. However, in the case of pAE-1, only $13 \%$ of the population remained showing the 'amylolytic phenotype'. These results indicated that the $E$. coli lysis phenotype was related to the expression of the foreign gene, and that the higher the number of copies of the gene the more toxic the phenotype was. During growth, cells with low or no levels of expression of the $l p l A$ gene could be selected; this may be the explanation for the delay found in the grow th curves.

\section{Only the $\mathrm{N}$-terminal domain of LpIA is involved in cell lysis}

To test the minimal sequence required to cause cell lysis, several clones were constructed that lacked different portions of the gene. Plasmid pAES-1 was constructed by eliminating the $0.5 \mathrm{~kb} S a c \mathrm{I}-P v u \mathrm{II}$ fragment from pAEP-1, and then religating. Plasmid pAES-1 11 was a $3^{\prime}$ deletion clone from pAES-1 which lacked both the leucine zipper and the transmembrane domain. Finally, pAES- $1 \Delta 2$ was constructed by fusing in frame a $5^{\prime}$ deletion clone from pAES- 1 and an EcoRI-BsmI fragment containing the regulatory sequences and the ATG codon of the gene; the fusion was checked by sequencing. These constructs were used to transform E. coli, and in each case, the appearance of the lysis phenotype was tested by the starch hydrolysis test (Fig. 4).

Plasmids pAES- 1 and pAES- $1 \Delta 1$ still showed a clear lysis phenotype, so the absence of the putative leucine zipper in the former (pAES-1), or the absence of the putative transmembrane anchor domain in the latter (pAES-1 $\Delta 1$ ), did not eliminate the lysis phenotype; therefore, they were not responsible for this phenotype. On the other hand, plasmid pAES-1 $\Delta 2$, which lacked the $\mathrm{N}$-terminal domain but still synthesized most of the protein, showed no lysis. Taking all these results together, we concluded that a domain located at the $\mathrm{N}$-terminus of the LplA protein was responsible for the lytic phenotype.

Recently it has been shown that the signal sequence of the S. pneumoniae ami $A$ and malX gene products was responsible for the lytic phenotype when these genes were expressed in E. coli (Martin et al., 1989). As shown in Fig.

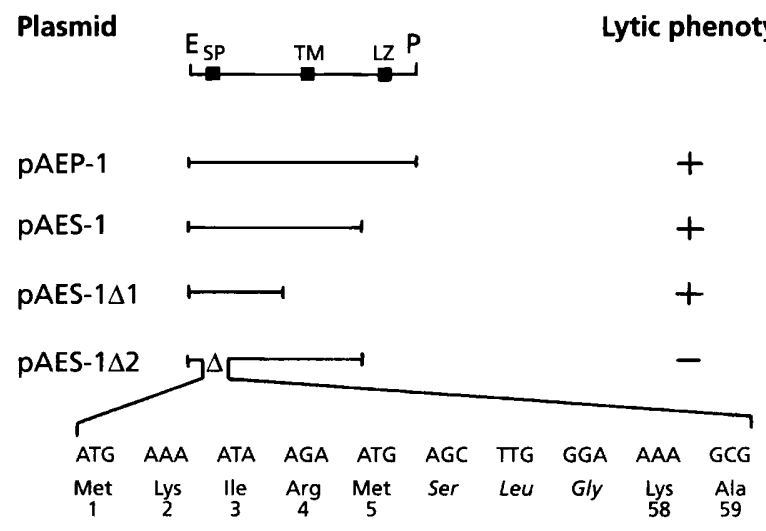

Fig. 4. Deletion analysis of the domain of LplA involved in cell lysis. The minimal sequence able to cause cell lysis was tested by constructing different plasmids that lacked different portions of the gene. See text for details. Amino acids in italic come from pUC and serve as a hinge between the $5 \mathrm{~N}$-terminal amino acids and the rest of the protein. SP, signal sequence; TM, transmembrane domain; LZ, leucine zipper; E, EcoRI; P, Pvull.

\section{Lpp \\ AmiA \\ MalX \\ PrsA \\ $P A L^{*}$ \\ PenP}

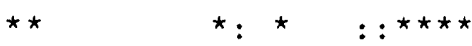

MKIRMRKKWMALPLAAMMIAGcshset MK. ATKLVLGAVILGSTLLAGCssnak MKKNRVFATAGLVLLAAGVLAACSSSkS MSSKFMKSTAVLGTVTLASLLLVACgskta MKKIAIAAITATSILALSACSSgdk MRYRAVFPMLIIVEALSGCt

\section{*PAL-related lipoprotein.}

Fig. 5. Homology between the $\mathrm{N}$-terminal domains of different Gram-positive lipoproteins, LpIA and the major $E$. coli lipoprotein (Lpp). Residues shown in lower-case letters correspond to the mature $\mathrm{N}$-terminal part of the proteins. Similarities between LpIA and Lpp are shown: identical amino acids are indicated by asterisks (*); similar amino acids are indicated by colons (:). Dots indicate gaps introduced in one sequence to give maximum correspondence. References: LpIA this work; Lpp, Martin et al. (1989); AmiA, Martin et al. (1988); MalX, Martin et al. (1988); PrsA, Simonen \& Palva (1993); PAL, Simonen \& Palva (1993); PenP, Simonen \& Palva (1993).

5 , there was a great deal of homology between the signal sequence cleavage sites of the E. coli Lpp lipoprotein, MalX and AmiA (from S. pneumoniae), other lipoproteins from Bacillus species and LplA (B. subtilis).

It has also been described that the expression of $S$. pneumoniae AmiA and MalX lipoproteins in E. coli resemble some phenotypes of the E. coli lp $p$ mutants, as sensitivity to EDTA (Martin et al., 1989). In order to demonstrate the EDTA sensitivity of $E$. coli cells containing the $l p l A$ gene, E. coli DH5 $\alpha$ was transformed with pAES-1 or with the vector alone (pUC13). pAES-1 was 


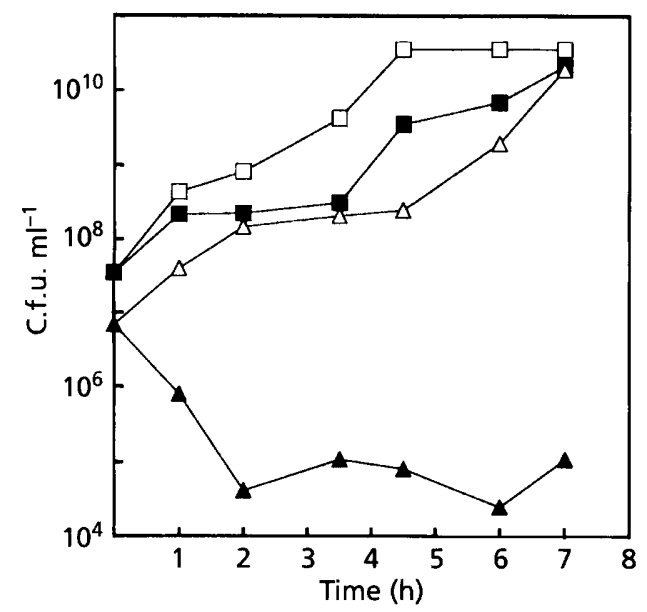

Fig. 6. EDTA sensitivity of $E$. coli transformed with different plasmids (see text for details). $\square$, pUC13-EDTA; pUC13+EDTA; $\triangle$, pAES-1 - EDTA; $\Delta$, pAES-1 + EDTA.

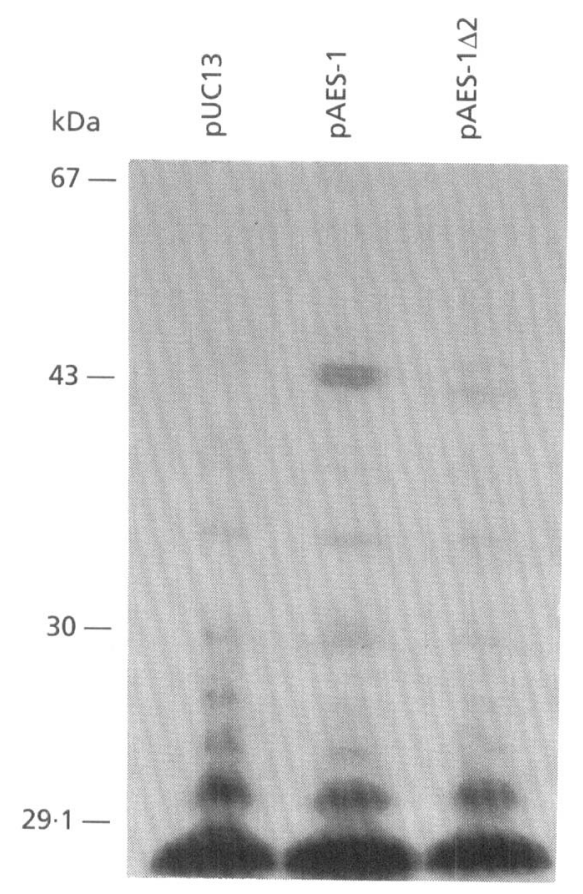

Fig. 7. Lipophilic modification of LpIA. E. coli cells were labelled with $\left[{ }^{3} \mathrm{H}\right]$ palmitic acid as described in Methods and the protein extracts analysed by SDS-PAGE and fluorography. Molecular size markers are on the left ( $k D a)$.

chosen since it showed greater phenotype stability than pAE-1. After 6 h growth, more than $90 \%$ of the cells still showed an amylolytic phenotype. Perhaps the downstream piece of DNA contained in plasmid pAE-1 could account for the different stability of the phenotype. Cells were grown overnight in $5 \mathrm{ml} \mathrm{LB}$ with $100 \mu \mathrm{g}$ ampicillin $\mathrm{ml}^{-1}$. A $250 \mu \mathrm{l}$ portion of the overnight culture was used to inoculate $50 \mathrm{ml}$ of fresh $\mathrm{LB} /$ ampicillin medium. Cells were grown at $37^{\circ} \mathrm{C}$ for $150 \mathrm{~min}$ and then the culture was divided into two aliquots of $25 \mathrm{ml}$. EDTA was added to a final concentration of $10 \mathrm{mM}$ to one aliquot and then all the cultures were grown at $37^{\circ} \mathrm{C}$. At different times, samples were taken from each culture and the c.f.u. per $\mathrm{ml}$ determined. As shown in Fig. 6, cells carrying pAES-1 were sensitive to EDTA, as has been observed in many mutants defective in the outer membrane. From these results, we inferred that the $B$. subtilis $l p l A$ gene may work in E. coli in the same way as do other lipoproteins. For this reason we named it $l p l A$ (lipoprotein like).

\section{LplA behaves as a lipoprotein in $E$. coli}

Further confirmation of the lipoprotein nature of LplA was its lipophilic modification by the addition of radiolabelled palmitic acid. As shown in Fig. 7, when E. coli cells carrying pAES-1 were incubated with $\left[9,10(\mathrm{n}){ }^{3} \mathrm{H}\right]$ palmitic acid for $1 \mathrm{~h}$, we were able to recover a lipoprotein band that corresponded to the expected molecular mass of the truncated LplA protein $(42 \mathrm{kDa})$. This lipoprotein was absent in E. coli cells transformed with the vector alone (pUC13) and also in cells transformed with the construction that lacked the $\mathrm{N}$-terminal domain of LplA (pAES-1 $\Delta 2$ ), confirming that this part of the protein was completely essential for the lipophilic modification of LPlA.

\section{DISCUSSION}

Cloning of genes encoding extracytoplasmic proteins in E. coli is sometimes difficult or even impossible, presumably because it leads to cell death (Henning et al., 1979). When the protein to be expressed is targeted to the membrane, the effects of its expression may be more deleterious since the protein may be anchored, altering the properties of these membranes. This seems to be the case when the LplA protein is expressed. The protein has a consensus $\mathrm{N}$-terminal signal sequence that may allow it to be translocated through the inner membrane of E. coli. LplA also contains a typical transmembrane anchor domain that may enable the protein to be anchored in the inner membrane, and a putative leucine zipper domain at the C-terminus, that may be involved in the oligomerization of the protein at the level of the membrane (Fig. 2). From our results (Fig. 4), we know that both the transmembrane anchor domain and the leucine zipper are not responsible for the lytic phenotype observed when the protein is expressed in E. coli. Only the $\mathrm{N}$-terminal domain of the protein seems to play a crucial role in cell lysis. Recently, it has been shown that signal sequences of other Gram-positive bacteria proteins are responsible for a lytic phenotype when they are expressed in E. coli (Gilson et al., 1988; Martin et al., 1989). It was suggested that the deleterious effects of these proteins could be directly related to the sequence of their signal peptides because they corresponded to the consensus cleavage sequence of $E$. coli lipoprotein precursors: Leu-Y-Z[cleavage site]-Cys-y-z; where $\mathrm{Y}$ is Ala, Ser, Val, Gln or $\mathrm{Thr} ; \mathrm{Z}$ is Gly or Ala; $\mathrm{y}$ is Ser, Gly, Ala, Asn, Gln or Asp; and $z$ is Ser, Ala, Asn or Gln [see Yamaguchi et al. (1988) for a review]. Normal lipoproteins in E. coli are exported through the cytoplasmic membrane, where the signal 
sequence is cleaved, and the $\mathrm{N}$-terminal cysteine is then transformed into a lipo-amino acid. This lipophilic modification is thought to be responsible for membrane anchorage of the lipoproteins. Due to the homology between the signal sequence of the E. coli lipoprotein LPP and the $B$. subtilis LplA protein we suggest that the E. coli export machinery would recognize the LplA signal sequence as a normal lipoprotein: the LplA N-terminal cysteine would be lipophilically modified and the protein would be anchored to the membrane by this lipophilic modification. Such a mechanism has been suggested for the export of MalX and AmiA lipoproteins (Gilson et al., 1988; Martin et al., 1989). In addition, the second amino acid of the LplA mature protein is a Ser, which seems to be a specific signal for targeting proteins to the outer membrane in E. coli (Gennity \& Inouye, 1991; Gennity et al., 1992). Sensitivity to EDTA (Fig. 6) suggests that the lytic phenotype was related to a depletion in regular lipoproteins, as has also been suggested for other Grampositive bacteria lipoproteins such as MalX and AmiA (Martin et al., 1989). The lipophilic modification of LplA with palmitic acid (Fig. 7) clearly demonstrates that the protein behaves as a lipoprotein in E. coli.

During the selection procedure, only clones carrying plasmids with different insert length but always containing the $\mid$ pl.A gene were picked up. Perhaps other B. subtilis lipoproteins could escape from the initial selection procedure because they gave a different colony phenotype or they were so toxic that cell gtowth was inhibited.

\section{ACKNOWLEDGEMENTS}

A. G. was supported by a grant from the Conselleria d'Educació i Ciencia (Generalitat Valenciana), and a grant from Bancaixa. The authors are indebted to Dr R. Serrano and Dr M. Espinosa for their useful discussions; to Dr G. Perez and Dr S. Bron for plasmid pGA14 and the Bacillus subtilis strain DB104; to Mr F. Marti for the photographic work and to Dr A. Flors for his constant support.

\section{REFERENCES}

Bolivar, F., Rodriguez, R. L., Greene, P. J., Betlach, M. C., Heyneker, H. L., Boyer, H. W., Crosa, J. H. \& Falkow, S. (1977). Construction and characterization of new cloning vehicles. II. A multipurpose cloning system. Gene 2, 95-113.

Bron, S. \& Luxen, E. (1985). Segregational instability of pUB110derived recombinant plasmids in Bacillus subtilis. Plasmid 14, 235-244.

Devereux, J., Haeberli, P. \& Smithies, O. (1984). A comprehensive set of sequence analysis programs for the VAX. Nucleic Acids Res 12, 387-395.

Gennity, J. M. \& Inouye, M. (1991). The protein sequence responsible for lipoprotein membrane localization in Eschericbia coli exhibits remarkable specificity. J Biol Chem 266, 16458-16464.

Gennity, J. M., Kim, H. \& Inouye, M. (1992). Structural determinants in addition to amino terminal sorting sequence influence membrane localization of Escherichia coli lipoproteins. $J$ Bacteriol 174, 2095-2101.

Gilson, E., Alloing, G., Schmidt, T., Claverys, J. P., Dudler, R. \&
Hofnung, M. (1988). Evidence for high affinity binding-protein dependent transport systems in Gram-positive bacteria and in Mycoplasma. EMBO J 7, 3971-3974.

Hanahan, D. (1983). Studies on transformation of Eschericbia coli with plasmids. $J$ Mol Biol 166, 557-580.

Henikoff, S. (1984). Unidirectional digestion with exonuclease III creates targeted breakpoints for DNA sequencing. Gene 28, 351-359.

Henning, U., Royer, H. D., Teather, R. M., Hindennach, I. \& Hollenberg, C. P. (1979). Cloning of the structural gene (OmpA) for an integral outer-membrane protein of Escherichia coli K12. Proc Natl Acad Sii USA 76, 4360-4364.

Hoop, T. P. \& Wood, K. R. (1981). Prediction of protein antigenic determinants from amino acid sequences. Proc Natl Acad Sci US A 78, 3824-3828.

Horinouchi, 5. \& Weisblum, B. (1982). Nucleotide sequence and functional map of pC194, a plasmid that specifies inducible chloramphenicol resistance. J Bacteriol 150, 815-825.

Marmur, J. (1961). A procedure for the isolation of deoxyribonucleic acid from microorganisms. J Mol Biol 3, 208-218.

Martin, B., Alloing, G., Boucraut, C. \& Claverys, J. P. (1989). The difficulty of cloning Streptococcus pneumoniae mal and ami loci in Escherichia coli: toxicity of malX and amiA gene products. Gene $\mathbf{8 0}$, 227-238.

Messing, J. (1983). New M13 vectors for cloning. Methods Enzymol 101, 20-78.

Pérez-Martinez, G., Kok, J., Venema, G., Van Dijl, J. M., Smith, H. \& Bron, S. (1992). Protein export elements from Lactococcus lactis. Mol Gen Genet 234, 401-411.

Priest, F. G. (1977). Extracellular enzyme synthesis in the genus Bacillus. Bacteriol Rev 41, 711-753.

Raha, M., Kawagishi, I., Müller, V., Kihara, M. \& Macnab, R. M. (1992). Escherichia coli produces a cytoplasmic $\alpha$-amylase, Amy A.J Bacteriol 174, 6644-6652.

Sambrook, J., Fritsch, E. F. \& Maniatis, T. (1989). Molecular cloning: A Laboratory Manual. Cold Spring Harbor, NY: Cold Spring Harbor Laboratory.

Sanger, F., Nicklen, S. \& Coulson, A. R. (1977). DNA sequencing with chain terminating inhibitors. Proc Natl Acad Sci USA 74, 5463-5467.

Schwartz, M. (1987). The maltose regulon. In Escherichia coli and Salmonella typhimurium: Cellular and Molecular Biology, pp. 1482-1502. Edited by F. C. Neidhardt, J. L. Ingraham, K. B. Low, B. Magasanik, M. Schaechler \& H. E. Umbarger. Washington, DC: American Society for Microbiology.

Smith, H., Bron, S., Ec, J. V. \& Venema, G. (1987). Construction and use of signal sequence selection vectors in E. coli and B. subtilis. $J$ Bacteriol 169, 3321-3328.

Willemot, K. \& Cornelis, P. (1983). Growth defects of Escherichia coli cells which contain the gene of an $\alpha$-amylase from Bacillus coagulans on a multicopy plasmid. J Gen Microbiol 129, 311-319.

Yamaguchi, K., Yu, F. \& Inouye, M. (1988). A single amino acid determinant of the membrane localization of lipoproteins in E. coli. Cell 53, 423-432.

Yang, M., Galizzi, A. \& Henner, D. (1983). Nucleotide sequence of the amylase gene from Bacillus subtilis. Nucleic Acids Res 11, 237-249.

Received 19 October 1993; revised 4 February 1994; accepted 11 March 1994. 